N. ${ }^{\circ} 31 \quad$ Julho-Setembro

Vol. XV - REVISTA DE HISTÓRIA - Ano VIII

\title{
CONFERENCIA
}

\section{AS UNIVERSIDADES MEDIEVAIS (*).}

Não vim fazer uma conferência, mas sim ministrar uma aula, na qualidade de professor e para dirigir-me aos primeiros alunos que se matricularam nesta Faculdade. Tendo sido fundada aqui em São José do Rio Prêto uma Faculdade de Filosofia e sendo eu um professor de História da Idade Média, achei que o melhor tema para esta aula, - aliás um dos pontos do programa que tenho a honra de prelecionar na Faculdade de Filosofia da Universidade de São Paulo, - seria justamente o seguinte: "As Universidades Medievais".

Tratando-se, pois, de uma aula, procurarei desenvolver o assunto da seguinte maneira: uma breve introduçẫo; a formação das Universidades - suas origens; a Universidade na primeira metade do século XIII, a Universidade na segunda metade do século XIII; na terceira parte a vida universitária na Idade Média e, para terminar, a decadência das universidades medievais.

\section{INTRODUÇÃo.}

Antes de mais nada é necessário que os srs. alunos tenham uma idéia do que foi a Idade Média. Costuma-se dizer errôneamente entre nós que a Idade Média foi um periodo de trevas. Não há êrro maior do que êsse. Houve de fato invasão de bárbaros, houve barbarização, mas esquece-se sempre de que se o Império Romano sossobrou, a Igreja permaneceu. A Igreja Católica recebeu a herança do Império Romano: haja visto a sua própria organização. A palavra bispo, convento, diocese, são oriundas dos quadros administrativos do próprio Império Romano. Foi a Igreja Católica que manteve a cultura, e que transmitiu para a época carolíngia, e daí para o século XIII, êsse facho cultural que vinha da Antigüidade.

Portanto, quando se diz que a Idade Média foi uma época de trevas é uma grande inverdade que se comete. $\mathbf{E}$ além do mais, nós somos talvez um pouco presunçosos, só pensando no Ociden-

\footnotetext{
(*). - Aula inaugural proferida quando da instalação da Faculdade de Filosofia, Ciências e Letras da Universidade Municipal de São José do Rio Prêto, em abril de 1957 .
} 
te e esquecendo o Império Romano do Oriente - Bizâncio que durante tôda a Idade Média manteve elevados elementos culturais que aliás propiciaram posteriormente para o Ocidente, como todos sabem, a chamada Renascença.

A palavra Universidade refere-se a uma coisa tìpicamente medieval. Foi empregada no sentido que usamos hoje, apenas no século XIII, como iremos ver, em Paris por exemplo, em 1261. Aparece com o sentido de comunidade - Universitas magistrorum et scholarium, ou então discipulorum; nestas condições é uma comunidade, uma corporação de professôres e de alunos. Com êste conceito só na Idade Média existiu a Universidade. Essa designação de Universidade, que é medieval, evidentemente referia-se a coisas que vinham de muito antes, com outros nomes, como por exemplo: studium ou então studium generale, palavras que designavem escolas mas que não tinham entretanto absolutamente o pleno sentido medieval de Universidade - comunidade de professôres e de alunos.

\section{FORMAÇÃO DAS UNIVERSIDADES.}

a). - Origens remotas da Universidade - $\mathrm{Na}$ Antigüidade houve escolas, por exemplo em Atenas onde o ensino superior era ministrado pelos filósofos gregos. Mas era ensino superior de homem para homem; ensino individual, e não havia, absolutamente, como na Universidade medieval, classes, não havia essa comunidade de alunos e de professôres. Também em Alexandria, no famoso Museu, eram ministrados cursos filosóficos e científicos. O mesmo se pode dizer de Pérgamo. Mas nada houve com o sentido atual de Universidade. A educação no mundo antigo era uma educação para as elites. Com o Cristianismo a educação antiga modifica-se. Por exemplo, em Antioquia já temos um sistema de ensino muito mais evoluído que o de Atenas, ou Pérgamo. Desde então a Igreja começa a interessar-se pelo ensino. Entretanto, podemos dizer que nesse período, as organizações precursoras das Universidades limitavam-se ao ensino da gramática em nível primário e da retórica em nível secundário.

Com o imperador Adriano houve uma tentativa de se estabelecer um curso escolar mais ou menos organizado. Cassiodoro retomou a mesma idéia; idéia prematura, entretanto, que não pôde ir adiante. Na Gália, Ausônio fêz também uma tentativa e houve escolas dignas de nota em Bordéus, em Narbona, em Toulouse, embora nada que se pudesse dizer uma Universidade. Gregório de Tours, no século VI, tentou mesmo organizar um curso, sob a forma duma comunidade de estudantes e professôres. Em Bizân- 
cio foi-se um pouco mais além. Justiniano, por exemplo, que teve grande interêsse em desenvolver o ensino do direito, procurou organizar cursos, mas como na Antigüidade, sempre para elites, visando a formação de administradores, de técnicos, etc. Bardas fundou uma escola: Manaura, com o mesmo fito. E um exemplo desta educação temos no próprio imperador Constantino Porfirogêneta, que foi um grande erudito, mas com uma formação que absolutamente não pode ser comparada com a de um universitário medieval e muito menos com a de um universitário de nossos dias.

$\mathrm{Na}$ Renascença carolíngia temos algo que se aproxima mais. da Universidade medieval do século XII. Vemos aí reunidos por Carlos Magno: Paulo Diácono, Pedro de Pisa, Teodulfo, Clemente da Escócia, Eginhardo, vejam, professôres de diversas regiões e, principalmente, o grande monge Alcuino. Mas é uma escola palatina, feita por Carlos Magno para formar os seus pagens, seus conces, seus clérigos. E ao lado da escola existia o famoso scriptorium, onde os monges copiavam os textos antigos. Nunca se esqueçam, com êste exemplo, o quanto hoje devemos à Igreja pela transmissão da cultura antiga. Nessa época não havia imprensa e era o monge quem copiava os textos antigos.

$\mathrm{Na}$ Inglaterra encontramos também centros culturais: Lindisfarme, Wearmouth, York, valiosas experiências de organização de escolas. O mesmo podemos ver no Continente em Bec, Corbie, Fleury, Fulda, S. Gall.

Tôdas essas escolas são escolas capitulares. Nasceram nas sacristias; nasceram junto das catedrais e dos conventos e são escolas para a formação de eclesiásticos e também para leigos. No século $\mathrm{X}$ floresce em Reims uma escola bem desenvolvida onde se destaca Gerbert D'Aurllac. Em Chartres evidenicia-se Fulbert, em Paris, Guilherme Champeaux e Abelardo. Mas a primeira Universidade, que podemos chamar de Universidade, aparece na primeira metade do século XI, no sul da Itália, em Salerno, próximo de Nápoles. Era uma escola de medicina onde se estudavam textos árabes que eram traduzidos para o latim ou então para o grego. Aí havia beneditinos e leigos. Ensinava-se ao lado da medicina árabe a medicina grega, a medicina de Galeno. Foi possível o nascimento dessa Universidade graças à dinastia dos Hohenstaufen que se preocupou muito com o problema do ensino, principalmente Frederico II que, apesar de sua vida irregular, é uma das. figuras mais curiosas de tôda a Idade Média.

b). - As Universidades na primeira metade do século XIII.

As Universidade multiplicam-se na primeira metade do século XIII. Antes já tinham sido fundadias as seguintes: Bolonha 
em 1088; Parma, em 1100; Paris, em 1120; Oxford, em 1130. No século XIII, em 1222, temos Pádua; e em 1224 Nápoles; em 1229, Toulouse; em 1288, Montpellier. Nunca devemos nos esquecer do seguinte: essas Universidade ministravam o ensino em latim, mas muita coisa vinha traduzida do mundo grego, através dos árabes que então ainda dominavam boa porção da Espanha. A cidade de Toledo era o centro onde eram traduzidos do grego para o árabe e do árabe para o latim, os textos de Aristóteles, de Platão e demais autores gregos. A essa eclosão de Universidades não é estranha a ciência greco-árabe.

As Universidades começam também a se preocupar com o direito romano. Com a invasão germânica, com a barbarização, foi introduzido o direito germânico, mas ainda ficara um resíduo do direito romano, principalmente através do direito canônico. Portanto nesse período nós sentimos uma coisa muita interessante: a acomodação do direito romano com o direito germânico e dêsse conúbio sairá um novo direito que reflete a miscigenação de invasores e de populações romanizadas.

Como vimos, as Universidades nascem sob os auspícios da Igreja. Em Paris, por exemplo, e nas cidades que foram enumeradas, é a Igreja quem inicia o movimento. Pouco a pouco, nas escolas, nas faculdades, recomeçam a ser ensinadas as artes, os decretos no que hoje seria a Faculdade de Direito _-, e mais a medicina, a teologia, tudo englobado sob o título Universitas magistrorum et scholarium.

Em Paris notamos que o Grão-chanceler orienta a Universidade da própria Igreja de Notre Dame e começa aparecer então uma reação contra êsse monopólio capitular. O Papa Inocêncio III oficializa a Universidade de Paris concedendo-lhe título e mais tarde Gregório IX outorga-lhe o sêlo. Pouco a pouco essa Universidade foi crescendo até que num certo momento procurou libertar-se completamente da tutela da Igreja e passou para a margem esquerda do Sena, onde aliás existe ainda hoje o Quartier Latin, que é o bairro dos estudantes e artistas.

E para mostrar até que ponto a Universidade medieval é obra da Igreja basta o seguinte: até o ano de 1400, das 44 universidades existentes, 31 foram fundadas pela Igreja mediante bulas, principalmente depois que os dominicanos e os franciscanos se lançaram às cátedras e ao ensino. Esses monges deixaram de lado as traduções árabes da filosofia grega e começaram a ir êles próprios às fontes. Assim se travaram na Universidade de Paris disputas entre os diversos professôres em tôrno de um texto, de uma palavra, disputas essas que tiveram enorme repercussão na cultura 
medieval. Houve disputas célebres sôbre textos de Aristóteles e Platão.

O direito canônico também entrou em choque com o novo direito civil que renascia do velho direito romano.

A realeza também protegeu a Universidade. Luís XI por exemplo, foi um grande protetor da Universidade de Paris, reconhecendo-lhe e amparando-lhe as greves, que paulatinamente acabaram também por serem reconhecidas até pela própria Igreja. O Papa Inocêncio IV reconhecia o direito de os estudantes e os mestres, se fôssem maltratados pelas autoridades civis ou eclesiásticas, declararem-se em greve. Vejam os senhores alunos portanto que a própria greve universitária nessa época tinha a bênção da Igreja, o que não acontece hoje em dia.

Em 1215 o famoso Estatuto de Robert Courçon delimita perfeitamente o bacharelado na Universidade de Paris: quantos anos eram necessários; a idade em que o jovem devia ingressar; com quantos anos êle poderia doutorar-se. O Estatuto aplica-se também nas faculdades de teologia - onde aliás era necessário ser mais idoso. Com êsse Estatuto de 1215 podemos dizer que já há uma estrutura da universidade parisiense. No bacharelado estudava-se a Introdução de Porfírio, a Sintaxe de Prisciano, Tópicas, Física e Metafísica de Aristóteles. A primeira lição de um mestre em artes devia basear-se no Livro de Sentenças de Pedro Lombardo. Um teólogo com três bacharelados e mais uma licenciatura obtinha o invejado grau de doutor em Teologia.

c). - As Universidade na segunda metade do século XIII.

A segunda metade do século XIII é o período de fastígio da Universidade medieval. Nunca se esqueçam que é a época em que pontificou São Tomás de Aquino. A famosa Summa de São Tomás é composta nesse período em que temos a Universidade Medieval mais típica. A Universidade de Paris cresceu de tal maneira que na segunda metade do século XIII a população estudantis de Paris orçava em cêrca de trinta mil estudantes (Bolonha, na Itália possuia vinte mil) e o maior número de estudantes estava matriculado na Faculdade de Artes que é justamente a antepassada da nossa Faculdade de Filosofia, Ciências e Letras. Lecionavase aí o Trivium: Gramática, Dialética, Retórica; e o Quadrivium: Música, Aritmética, Geometria e Astronomia, divisões essas que vinham aliás do mundo antigo. Esta Universidade é uma Universidade internacional. Havia o que na época se chamavam: "as nações": nações de estudantes. Os gallicani (a honrada nação dos galicanos, era o nome que ela tinha nos documentos) eram indivíduos oriundos de Paris, de Bordéus, da Espanha, da Itália. A outra 
nação, a dos Normandi (venerável nação dos Normandi) compreendia os estudantes oriundos da Normandia. Os Picardi (também chamada a muito fiel nação dos Picardi) compreendia os alunos vindos da Flandres; e por fim na "nação" dos Angli ou Alemani (a muito constante) matriculavam-se os estudantes da Inglaterra, da Alemanha, da Escócia, da Irlanda, da Escandinávia, Polônia, Hungria e Boêmia. Os professôres eram das mais variadas procedências: Alberto o Grande, por exemplo, era alemão de Colônia: Alberto da Boêmia (da Checoslaváquia dos nossos dias); Sigério de Brabante, da região de Flandres; São Boaventura e Santo Tomás de Aquino, italianos. Vejam os srs. estudantes, que já naquela época beneficiava-se extraordinàriamente a Universidade com a vinda de professôres estrangeiros que traziam a cultura de seu povo para que os seus novos estudantes pudessem também dela aproveitar-se.

A Universidade era regida por um Conselho de Procuradores, eleitos pelas diversas "nações", e êsse Conselho escolhia o Reitor, que naquela época, era quem convocava o conselho dos mestres. Havia também o Grão-chanceler. Aqui há um diferença entre Paris e Bolonha. Na Universidade de Paris o Grão-chanceler foi durante muito tempo a figura mais importante, ao passo que, em Bolonha, era o inverso que se dava. Em Bolonha, a Universidade se especializou mais no Direito, e nas moedas da época havia sempre a divisa Bononia mater studiorum, Bononia docet. Esta Universidade de Bolonha recebeu um grande impulso com Frederico Barbaruiva, que tinha um grande interêsse em que o Direito Romano fôsse restaurado porque era justamente um apôio à sua política imperial.

Em 1250, temos na Universidade de Bolonha duas "nações": a Universitas citramontanum (onde se grupavam os italianos) e a Universitas ultramontanorum (onde se reuniam principalmente os estudantes alemães - theotonici), os estrangeiros eram todos ultramontanos. Aí estudava-se o direito, principalmente o Direito Romano; e havia inúmeros alemães, homens mais idosos, geralmente clérigos, que vinham estudar com bôlsas dos governantes alemães.

Outra Universidade típica dêsse período é a Universidade de Oxford, onde tiveram grande predomínio os franciscanos. Foi erigida a duzentos quilômetros de Lincoln, na Inglaterra, sob a égide do bispado. Como o bispo estivesse longe a Universidade adquiriu uma certa independência. Aí pontificou o famoso monge Robert Grossetête, que conhecia o hebreu e o grego; nessa época isso era uma coisa verdadeiramente espantosa: um homem conhecer e falar o grego e o hebreu. Este Robert Grossetête não se dedicava exclusivamente aos estudos filosóficos, procurava também desenvol- 
ver as ciências naturais. Outro grande nome da Universidade de Oxford foi Roger Bacon ou Rogério Bacon que todos os srs. conhecem. O ensino da mecânica foi aí introduzido, veja-se o De secretis opibus artis et naturae. Desta Universidade, por uma secessão, em virtude de uma luta dos estudantes e dos seus professôres contra as autoridades civis, sairam aquêles que fundaram a Universidade de Cambridge.

Na Espanha, Salamanca é uma grande Universidade nesse período. Temos também Sahagum (fundada por Afonso VI), Palência criada por Afonso VIII. Salamanca foi fundada por Afonso IX, mais tarde transformada por Fernando III. Sem dúvida Salamanca é o centro mais importante. Ensinavam-se aí línguas, retórica, medicina, música, direito, teologia. Havia estudantes de diversas procedências. Os Estados ibéricos procuravam fundar Universidades para evitar que seus estudantes fôssem para Paris, ou Bolonha. Queriam retê-los em sua própria casa. E falando da Península Ibérica evidentemente não podemos deixar de falar da nossa Célula Mater - Coimbra.

Nos séculos XII e XIII embora houvesse em Portugal escolas nos mosteiros, como por exemplo em Alcobaça, Santa Cruz de Coimbra, etc., os jovens portuguêses, em busca de ensino superior, iam: para Salamanca, Bolonha, Montpellier. Foi então que El-Rei D. Diniz, recebendo pedido de clérigos interessados, procurou fundar uma Universidade para reter êsses elementos em Portugal.

A Universidade foi criada em 1 de março de 1290 mediante bula de Nicolau IV, em Lisboa; em 1308 D. Diniz a transferiu para Coimbra. Nessa Universidade instituiu-se estudo de Direito Canônico, Direito Civil, Medicina, Gramática, Dialética. A Teologia foi ministrada por franciscanos e dominicanos. Em 1338 voltou para Lisboa com Afonso IV; em 1354 retornou para Coimbra; em 1377 tornou a voltar para Lisboa. Enfim, acabou ficando mesmo em Coimbra e lá ainda se encontra hoje em dia. Nessa Universidade em Direito costumava-se estudar prircipalmente as obras de Bártolo, e havia mesmo um livro na Biblioteca de Lisboa que era prêso por uma corrente, na época de $D$. João I, talvez para que - estudante não o levasse para casa. Essa Universidade desenvolveu-se muito com a proteção do Infante D. Henrique, o Navegador que subvencionou cadeiras de Matemática e de Astronomia, evidentemente para melhor preparo dos pilotos de que tanta $n \geqslant-$ cessidade tinha para os seus empreendimentos náuticos.

\section{A VIDA UNIVERSITÁRIA.}

E agora vejam a vida universitária dessa época. Como ensino temos a lectio e a disputatio. A lectio era preleção e a disputatio 
- debate universitário entre mestres e alunos ou então entre os próprios alunos. Da lectio tiravam-se conclusões e silogismos, etc. Como se vê, o ensino era exclusivamente oral. A disputatio se fazia uma vez por semana - é a nossa sabatina, o nome ainda perdura . O magister fazia uma conferência, propunha um certo número de princípios (tesis) perante outros professôres (oponentes), Nesse debate argüia-se e respondia-se (arguere e respondere).

Há também o problema do salário. Os alunos sustentam os professôres, que viviam das taxas que cobravam pelo seu ensino. Proibia-se a um professor receber aluno devedor de outro mestre. Como os alunos geralmente eram pobres, foram instituídas bôlsas de estudo; diversos fidalgos, diversas instituições mantinham essas bôlsas. Não constitui pois novidade a concessão de bôlsas de estudos, hoje tão comuns entre nós.

As vestes eram geralmente talares, daí o estudante ser conhecido na França medieval como o clerc, que é a tradução de clérigo. Os professôres e estudantes usavam roupas bem parecidas e ambos, tanto os professôres como os estudantes, tinham uma vida tôda eclesiástica. Estudantes e professôres não podiam casar-se. Se casassem seriam expulsos da Universidade; isso foi no comêço, é óbvio, depois a coisa mudou. O aluno usava um capuz e o professor um barrete.

Havia nessa época, como era geral na Idade Média, uma organização eminentemente corporativa. Há uma hierarquia na organização: escolares (pagens, escudeiros, cavaleiros), bacharéis, os mestres, divididos em bas chevalier (baccalarius) e chevalier. Essa organização assemelha-se muito à da nobreza.

Começa a aparecer também alojamentos em comum onde os estudantes se congregavam. Em 1257 Roberto de Sorbon faz doação de um prédio para alojamento de estudantes, e, assim, funda-se - Collegium Sorbonnicum que é a Sorbonne dos nossos dias, na França. E dessa data até 1500 temos cêrca de 50 colégios semeThantes à Sorbonne em Paris. Mas aqui assistimos a uma coisa interessante: a Universidade de Paris absorve os colégios e o contrário acontece na Inglaterra onde os colégios absorvem a Universidade. Ainda hoje o ensino inglês é feito por colégios - os college - por exemplo o College of Trinity. Tivemos na nossa Faculdade de Filosofia um professor inglês que se orgulhava de pertencer a um dos tradicionais colleges da Universidade de Oxford. Como vemos, até hoje perdura essa organização.

$\mathrm{E}$ havia também o trote, com tôdas as características bem conhecidas de todos nós. Na Idade Média, em Paris, a famosa peruada chamave-se o bean, le bec jaune, o bico amarelo. Fantasias com chi- 
fres, dentes, cabelos, barbas postiças, enfim, havia uma espécie de carnaval na recepção aos calouros.

Não podemos deixar de mencionar os goliardos, que eram estudantes que perambulavam e eram chamados vaganti, que andavam de escola em escola e possuiam costumes deploráveis. Criticavam o Papa e o clero, faziam versos satíricos em latim. Criaram uma ordem, a Ordem do Bispo Golias. Verdadeira paródia das ordens monásticas. Aliás Abelardo, o famoso Abelardo, manteve contacto com êsses elementos e por isso foi acusado por São Bernardo de ser também um goliardo; aliás, São Bernardo chamava-o de Golias. Na segunda metade do século XIII êsses goliardos entraram em decadência. Daixaram uma poesia interessante por ser espontânea, nascida que foi do vinho, do amor, mas seus costumes deixavam muito a desejar. A mais célebre de suas poesias era: Meum est propasitum in taberna mori e o mais famoso goliardo foi Tomás Platter. Mas êsses goliardos desapareceram pouco a pouco, como não poderia deixar de acontecer, devido o fortalecimento do poder real que passu a reprimir êsses abusos.

Os universitários constituiam corporação à parte, possuinds inúmeros privilégios, sendo mais importantes os seguintes: isenção de serviço militar; dispensa de taxas, impostos e contribuiçôes; direito de conceder a licença de ensino, isto é, é a Universidade que concede a outrém o direito de lecionar.

DECADÊNCIA DAS UNIVERSIDADES MEDIEVAIS.

Ora, essas Universidades cresceram, tiveram um período de fastígio no século XIII, mas como acontece com tôdas as coisas, veio depois o período de decadência da Universidade medieval. $\mathrm{E}$ esta decadência é oriunda principalmente da Guerra dos Cem Anos. Foi uma guerra difícil, em que França e Inglaterra se degladiaram de uma maneira tremenda $\mathrm{e}$, em consequiência da guerra, houve fome por tôda a parte; houve peste, e conseqüentemente o próprio ensino deixou muito a desejar. Não faltou vontade de instruir, de abrir escolas. Não são as escolas que faltam; há muitas Universidades; muitas se fundam nesse período, mas o que mudou foi o ensino, foi o conteúdo. A Antigüidade mal conhecida até então, agora entra de roldão na vida cotidiana, com a fuga dos mestres de Bizâncio para o Ocidente, em consequiência da tomada daquela cidade pelos turcos.

A escolástica entrou num período, não digo de decadência, mas de grandes mutações, sem vontade de lutar, perdendo fôtças em discussões estéreis em tôrno de pequenas coisas. E uma prova da decadência dessa Universidade temos na execução de 
Joana d'Arc, que foi condenada pela Universidade de Paris como feiticeira.

Concluindo, podemos dizer que a Renancença fêz com que a Universidade medieval morresse. Vai nascer uma outra Universidade muito diferente. Um fator importantíssimo da decadência foi o Estado fundar Universidades novas e intervir nas ve1has. Estas deixaram pois de ser uma corporação de mestres e alunos. Portanto, a Universidade medieval morre com a própria Idade Média. Com a Renascença, com métodos novos, coisas novas, novos ideais, evidentemente essa Universidade não podia subsistir. Aparecem métodos completamente diferentes de ensino, novas idéias, o próprio espírito universitário mudou. $O$ estudante também procurava coisas novas, ciências novas que êle absolutamente não podia encontrar na Universidade medieval. Por tudo isso ela morreu.

E com isto nós encerramos a nossa aula. Muito obrigado.

\section{E. SIMÕES DE PAULA}

Professor da Cadeira de História da Civilização Antiga e Medieval da Faculdade de Filosofia, Ciências e Letras da Universidade de São Paulo. 